\title{
Developmental Mode for Circular Economy in the Yellow River Delta
}

\author{
Zhang Xu-Liang, Zhang Zhao-Hui, Xu Zong-Jun, Yao Hai-Yan, and Zheng Ke-Fang
}

\begin{abstract}
Due to high strength use of natural resources and large quantity of pollutants discharge, high pressure is given to the fragile environment of the Yellow River Delta, so circular economy should be developed in the Yellow River delta. At present the circular economy has been developed in an elementary scale in the Yellow River delta, yet there are also some factors which have limited the circular economy development, such as inadequate understanding of the importance of circular economy, unreasonable industry structure, lack of policy and technical support, fragile environment and too much pollutants discharge. The authors also proposed some countermeasures for circular economy development in the Yellow River Delta, such as constructing the industrial structure which fits for the requirements of circular economy development, reducing energy consumption, improving the natural resources using efficiency, promoting the ecological construction of oil field and the coordinated economy development of oil field and local area, vigorously developing the marine circular economy, constructing ecological city, and creating a circular society and etc.
\end{abstract}

Index Terms-Industrial cluster, industry chain, energy saving and consumption reducing, Yellow River Delta.

\section{INTRODUCTION}

Circular economy takes efficient and recycling utilization of resources as its core, reduction, reuse and recycle as its principle and low input, low consumption, low emission and high benefit as its feature, all of which conform to the concept of sustainable development [1]. In practice, circular economy includes enterprises, industrial park, urban and regional levels [2]. Circular economy makes reasonable use of natural resources and environmental capacity in order to realize the ecological transition of economic activities. It is an economic model of sustainable development, and it is

Manuscript received June 1, 2013; revised July 29, 2013. This work was supported by Shandong Provincial Key Laboratory of Marine Ecology and Environment \& Disaster Prevention and Mitigation, China (2012002), the Special Funds Projects for Public Welfare of National Ocean Industries, China (201105005).

X.-L. Zhang is with the Department of Geography, Normal College, Qingdao University, NO. 308 Ningxia Road, Qingdao 266071, China; Shandong Provincial Key Laboratory of Marine Ecology and Environment \& Disaster Prevention and Mitigation, Qingdao, 266033, Shandong, China (e-mail: Geo_zhang@163.com).

Z.-H. Zhang and Z.-J. Xu are with the First Institute of Oceanography, State Oceanic Administration, NO. 6 Xianxialing Road, Qingdao 266061, China (e-mail: zhang@fio.org.cn).

H.-Y. Yao is with the North China Sea Environmental Monitoring Center, State Oceanic Administration, Qingdao 266033, China; Key Laboratory of Marine Spill Oil Identification and Damage Assessment Technology, State Oceanic Administration, Qingdao 266033, China (e-mail: yaohaiyan-y (a)163.com).

K.-F. Zheng is with the North China Sea Environmental Monitoring Center, State Oceanic Administration, Qingdao 266033, China (e-mail: bhxxzx_zgb@bhfj.gov.cn). useful to ease the contradiction between regional development and population, resources as well as environment [3], [4]. Some other scholars also have carried out many case studies of circular economy. For example, Feng and Yan proposed an implementation framework of circular economy in China and some methods of practically implementing a circular economy in China in 2007 [5]. Li and $\mathrm{Yu}$ researched legislative and policy tools for promoting the circular economic model for waste management in China in 2011 [6]. Andersen explained in detail some fundamental principles and approaches in environmental economics of circular economy in 2007 [7]. Developing circular economy in Yellow River delta is the principal means to implement the national strategies of Yellow River delta high-efficiency economic zone and Shandong Peninsula blue economic zone, to realize the economic growth mode transformation, adjust economic structure, and to realize the regional sustainable development. It is also the inevitable choice of Dongying city to construct ecological city and marine ecological civilization [8].

\section{THE CHARACTERISTICS OF RESOURCE, ENVIRONMENT AND ECONOMY OF YELLOW RIVER DELTA}

\section{A. The Characteristics of Resource, Environment of the Yellow River Delta}

The Yellow River delta $\left(118^{\circ} 5^{\prime}-119^{\circ} 15^{\prime} \mathrm{E}, 37^{\circ} 15^{\prime}\right.$ $\left.38^{\circ} 15^{\prime} \mathrm{N}\right)$ is located on the west coast of Bohai sea, China (Fig. 1). It starts from Ninghai town, Kenli county as its vertex and reaches northward up to the estuary of Taoer River, and reaches southward to the estuary of Zimai River in Dongying city, Shandong province. It is accumulated since the burst of the Yellow River at Tongwaxiang in Henan province and rechanneled into Daqing River and then into Bohai sea in 1855, covering a land area of about 5400 $\mathrm{km}^{2}$ [9]. The length of coastline of Dongying city is 350.4 $\mathrm{km}$, its area of shallow sea less than $15 \mathrm{~m}$ in depth is 4800 $\mathrm{km}^{2}$ and its area of intertidal zone is $1154 \mathrm{~km}^{2}$. The coast of Yellow River delta is abundant with sunlight, heat, wind, fresh water, land, petroleum and natural gas, underground salt water, terrestrial heat, creatures and other natural resources, which is beneficial to the regional economic development. The delta has a short forming history and the coastal wetland ecosystem in its outer margin is in the early stage of its evolution, because of which the environment is fragile----the marine disasters such as storm surge, waves, coastal erosion, sea ice, the other disasters such as floods and drought which occur with big intensity and high frequency, the high salinization of soil in supratidal zone, the simple structure of plant community with less species. The fragile environment and the disasters mentioned above restrict the development of circular economy and marine 
economy of the Yellow River delta.

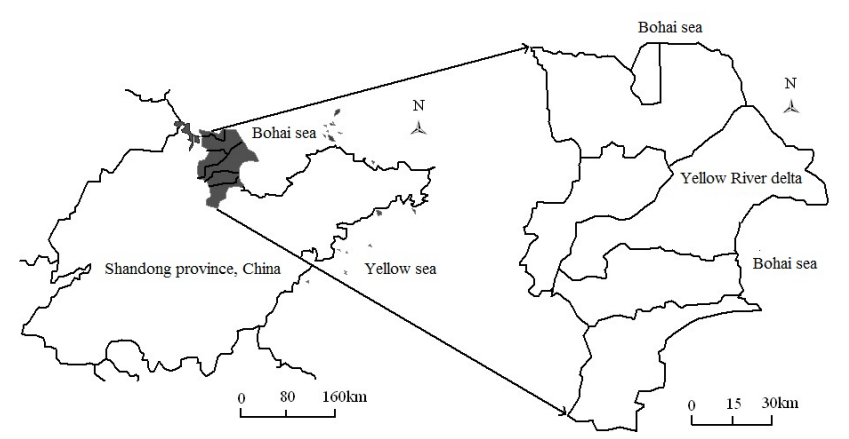

Fig. 1. Location of Yellow River delta, northern China

\section{B. The Situation of Social and Economic Development in} the Yellow River Delta

Dongying city, Shandong province $\left(118^{\circ} 7^{\prime}-119^{\circ} 10^{\prime} \mathrm{E}\right.$, $36^{\circ} 55^{\prime}-38^{\circ} 12^{\prime} \mathrm{N}$ ) located in the Yellow River delta, it is adjacent to Zhanhua and Boxing counties, Binzhou city in the west, and Linzi district of Zibo city and Shouguang, Qingzhou of Weifang city in the south. The land covers an area of $7923 \mathrm{~km}^{2}$ with a population is 1.86 million. The city was established on October 1, 1983 to exploit Shengli oil deposit. The economy of Dongying city is relatively developed. It realized its regional GDP of 267.635 billion Yuan RMB in 2011, with a rise of $12.7 \%$ from 2010 account by comparable price, among which, the first industrial added value was 9.918 billion Yuan RMB, the second industrial added value was 191.481 billion Yuan RMB and the tertiary industry added value was 66.236 billion Yuan RMB, the industrial three-time structure was 3.7:71.6:24.7. Dongying city had achieved the GDP per capita of 143900 Yuan RMB in 2011, which was 3.04 times of it of Shandong province 47300 Yuan RMB, and 4.10 times of the national GDP per capita 35100 Yuan RMB [10].

\section{The Necessity AND Situation OF THE CiRCUlaR}

\section{ECONOMY DEVELOPMENT IN THE YELLOW RIVER DELTA}

\section{A. The Necessity of the Development of Circular} Economy in the Yellow River Delta

Due to backward technology and extensive management, the use of natural resources in Dongying city features high strength, low efficiency and large pollutant emissions. For example, in 2010, industrial wastewater emissions of Dongying city amounts to $1.06 \times 10^{8} \mathrm{t}$, solid waste emissions attains to $240.46 \times 10^{4} \mathrm{t}$ and the energy consumption of ten thousand Yuan RMB GDP is $0.65 \mathrm{t}$ of standard coal, the water consumption of ten thousand Yuan RMB GDP is $59.75 \mathrm{~m}^{3}$, while the industrial water reuse rate is only $78 \%$, water use coefficient of irrigation is only 0.57 , GDP output of construction land per area is $181 \times 10^{4}$ Yuan $\mathrm{RMB} / \mathrm{ha}$, main renewable resources recovery utilization rate of $65 \%$, urban reclaimed water utilization rate is only $10 \%$. All the above have put great pressure on the environment of the Yellow River delta. On the other hand, the environment is fragile, and the need to develop recycling economy in the Yellow River delta is urgent.

\section{B. The Development Situation of Circular Economy in the Yellow River Delta}

The industrial chains of circular economy are in proposed shape. To promote intensive and cascade utilization of resources and energy, and to develop leading enterprises into leading industry chain and network, the Yellow River delta has basically formed a circular economy industrial chain which takes circular economy enterprises as the fulcrum and is supported by the circular economy park of chemical petroleum industry, papermaking, chemical salt industry, rubber tires, seawater desalination, electricity, textile, comprehensive waste utilization of agriculture and forestry and so on. Cultivate formed a petrochemical, salinization, papermaking, textile, nonferrous metals, rubber tires, such as the leading industry of Huatai group, Wanda group, Fangyuan nonferrous metal co., LTD., etc. 20 enterprise and 25 projects of circular economy, 3 municipal or higher level industrial circular economy parks, among which Dongying economic and technological development zone and Victory industrial park are provincial level circular economy demonstration parks. Based on the construction of industrial circular economy chain, enterprise, project and circular economy park and its constant improvement, Dongying city saves energy of $4.3 \times 10^{4} \mathrm{t}$ of standard coal annually.

Obvious advantage of industry clusters. In recent years, the industrial enterprises in Yellow River delta continuously transform their development mode, constantly optimize their structures of productions and organizations, and the industry clusters of chemical industry, petroleum equipment, textile, garment and auto parts industries are initially formed. As an important organization form and the carrier of industry, the industry clusters can effectively make up for all the shortcomings of the Yellow River delta, the proportion of small and medium-sized enterprise quantity is high and that the individual enterprise does not have a loop condition. And all this helps to implement the ecological transformation of the industrial parks, to promote the formation of ecological circular economy industrial chains, and to realize centralized supply of heat and gas and reduce pollution, recycling waste, etc.

Enhanced unceasingly industrial energy saving. By implementing energy saving assessment review and amount of obsolete policy, control new energy-intensive, highly polluting projects from start. In 2010 the city received 206 energy saving assessment programs of investment in fixed assets, among which 175 were for the record, 31 for review and 61were energy-consuming projects, effectively keeping the "high-polluting, high- energy-consuming and resource-dependent" projects within limits. In addition to close down backward production facilities more quickly, since the "11th five-year plan" has eliminated a large number of backward production capacity products such as the 50t shaft kiln cement diaphragm and $6 \times 10^{4} \mathrm{t}$ caustic soda unit, 611 sets energy-intensive electrical equipment, $25 \times 10^{4}$ spindles, $360 \times 10^{4}$ bias tyre, $7.5 \times 10^{4} \mathrm{t}$ paper making, $200 \times 10^{4}$ t petrochemical devices, and so on. In consequence, each year $68 \times 10^{4} \mathrm{t}$ of standard coal consumption is reduced and $52.1 \times 10^{4} \mathrm{kw}$ small power plants were shut down, finishing the "the 11th five-year plan" task ahead of the time set by the provincial government. 
Remarkable progress has been made in building the agricultural circular economy. With the implementation of ecological agriculture demonstration county construction engineering, crop straw stalk comprehensive utilization project and rural renewable energy exploitation and utilization project, the city has built three pilot ecological agriculture demonstration counties, the construction with "a pool of three change" (to build a biogas pool and to transform the kitchen, pigsty and toilet at the same time) as the main mode of rural household biogas digester. $5.5 \times 10^{4}$ medium-sized pools and 14 large pools as well as 122 medium-sized pools have been built. $136 \times 10^{4} \mathrm{t} / \mathrm{a}$ of crop straw has been comprehensively utilized, the straw utilization rate attains to $85 \%$; Measured soil fertilizer project implementation area amounts to $20 \times 10^{4}$ ha; 16 various integrated pest management demonstration zones have been established, covering an area of $6.12 \times 10^{4}$ ha. A green, organic, pollution-free agricultural production base of $11.27 \times 10^{4}$ ha was founded, certificating 264 green, organic, pollution-free agricultural products [10].

Steady growth of circular economy of construction has been achieved. For the circular economy development of architecture, Dongying city strictly implements the building energy efficiency standards, and its energy-saving building completion area has accounted for $100 \%$ in urban districts. Use of solid clay bricks are completely banned in towns and villages, the use of harmful materials in building construction are reduced or eliminated, the application of new wall materials are increased. 99 new wall materials enterprises have produced new wall materials $19.02 \times 10^{8}$ standard brick which save land 134.17 ha, save energy of $14.11 \times 10^{4} \mathrm{t}$ of standard coal, use waste residue of $358.69 \times 10^{4} \mathrm{t}$, and reduce $\mathrm{CO}_{2}$ emissions of $37.62 \times 10^{4} \mathrm{t}$. New wall material production takes up $100 \%$ of the total wall building materials in the city.

Advanced and new technology industries and modern service industry have developed. The high-tech industrial output of Dongying city in 2010 accounts for $25.44 \%$ of the total value of industrial enterprises above designated size, $11.91 \%$ higher than that at the end of "the tenth five years"; The added value of service industry as a share of GDP reached $23.7 \%, 7.6 \%$ higher than that at the end of the tenth five years [10].

New energy has been used and energy consumption structure has been optimized. Through using new energy and renewable energy, Dongying city has optimized the energy consumption structure. The wind power installing capacity attains to $45 \times 10^{4} \mathrm{kw}$, yearly electricity generation attains to $7.82 \times 10^{8} \mathrm{kwh}$, yearly electricity generation by using biomass energy attains to $2.23 \times 10^{8} \mathrm{kwh}$, the two of which devote a total of $35.18 \times 10^{4} \mathrm{t}$ of standard coal; Solar power generation is starting to take shape, with an annual output of $50 \mathrm{MW}$ solar battery, saving accumulating power of $7900 \mathrm{t}$ of standard coal [10].

Obvious effects have been posed on environment protection and ecological construction. During the period of "11th five-year plan" of China, Dongying city has been identified as "international green industry demonstration zone", "national health city", "national environmental protection model city", carrying out ten big model projects such as the blue sky city engineering, clean water engineering, health engineering and ecological engineering and so on, having launched key infrastructure projects such as water and soil protection content, ecological forest construction and small watershed governance in the coastal zone, creating 4 national beautiful environment townships and 6 provincial beautiful environment townships in the country [10].

\section{RESTRICTIVE FACTERS IN DEVELOPING CIRCULAR ECONOMY IN THE YELLOW RIVER DELTA}

\section{A. Insufficient Understanding of the Importance of Circular Economy}

Current government still has an insufficient understanding of the urgency and importance of developing circular economy, enterprise awareness of environmental protection has not shifted from terminal management to process control, reduction of resources consumption and clean production; the social public awareness of resource conservation and environmental protection is not strong, and the phenomenon of land, water, electricity and other resources waste is still very prominent.

\section{B. Unreasonable Industrial Structure}

Extensive pattern of economic development, low level of structure are always the outstanding problems of the economic development of Dongying city, at present the proportion of the 3rd industry structure of Dongying city is not balanced, relying mainly on industrial development to drive economic growth. Tertiary industry featuring low consumption and low pollution occupies a strikingly low proportion in the national economy. Industries of internal resources, processing and extensive industries is still high in proportion, and the number of new and high technology enterprises is still small.

\section{Low Correlation between Different Enterprises and Industries}

There has not yet formed a full formation twisted chain between the products of the main industry at present Dongying, and thus lack the mutual use and complementation in between. Relationship between enterprises is loose, the degree of regional collaboration is low, product homogeneity is strong, the correlation degree is low, and public resources mutually regime, and as a result a circular economy framework has not really fully established. Most enterprises have a short internal chain with narrow coverage of production, and with low level of by-products deep processing and waste recycling. The product line is still far from enough to extend.

\section{Lack Support of Policy and Technology}

The Dongying city is lack of policies to support the development of circular economy, to inspire and arouse the enthusiasm of industry enterprises to develop circular economy. Specific technical measures of developing circular economy is still not mature enough, lacking waste recycling and disposal of industrial chain technology and the low-input, short-term pollution control technology, clean production technique, the application technique of ecological industrial links, and so on. 


\section{E. Fragile Environment and Big Pollutant Emission}

The Yellow River delta is vulnerable to damage since it has a short time of land formation, a low environmental capacity, and a fragile environment. It is difficult to recover once it is damaged. Now there are still contradictions in the Yellow River delta between a big pollutant emission and a small environmental capacity. Structural pollution by various industry departments is still obvious. The two industries of papermaking and oil refining sewage accounts for more than $70 \%$ of the total water pollution load; air pollution by electric power and oil refining industry accounts for more than $80 \%$ of the total load of air pollution; besides, excessive and illegal emission of wasted and polluted water occurs frequently, serious threatening the safety of river water quality; Solid waste disposal rate is not high, the battery and other waste pollution is aggravating. Fertilizers and pesticides are too much, prominently polluting agriculture; the number of city motor vehicles grows rapidly, causing serious chemical smoke exhaust pollution and light pollution.

\section{COUNTERMEASURES OF CIRCUlAR ECONOMY DEVELOPMENT IN YELLOW RIVER DELTA}

\section{A. Format Reasonable Industry Structure to Meet the Requirements of Circular Economy}

Optimize the industrial economic structure. Promote applications of advanced energy-saving technologies to raise the levels of chemical, paper, tires, textile and other traditional industrial technology. Develop new materials, biological medicines, electronic information, new and high technology industries and modern manufacturing industries. Construction of industrial park is the most effective way to realize the industrial concentration [11]. Promote industrial projects and strypped-down oilfield enterprise agglomeration to the industrial park zone, and to orientate a dislocated development mode of the enterprises. Encourage the enterprises to exploit new upstream and downstream products of industrial chains, and to develop industrial supporting projects, by means of which industrial chains will be extended, the industry integration will be promoted, industrial clusters will be fostered.

Optimize the structure of agricultural economy. Circular economy is the inevitable choice of sustainable agriculture development strategy [12]. According to the regional distribution and the overall requirements of industrialization and standardization of production, agricultural resources should be allocated reasonably, agricultural ecological conditions should be improved, an agricultural circular economy system with characteristics of efficient production and ecological coordination should be formed.

Optimize the structure of the tertiary industry. Vigorously develop modern service industry, raise its proportion in the whole national economy; Develop tourism, business and consumer services, build economical transportation system and improve transport efficiency, strive to break through the design of research and development of modern logistics, finance, insurance, and other producer services, increasing the services sector share of GDP year by year.

\section{B. Energy Saving, Improve the Utilization Efficiency of Natural Resources}

Focus on promoting energy conservation of industrial enterprises. Push energy conservation work among key industries such as papermaking, textile, chemical, electric power and others as well as key energy- consuming enterprises above municipal level. According to the principles of controlling increment, adjusting inventory, constructing big enterprises, supporting the superior enterprises and phase out the inferior enterprises, strictly control new high energy consumption and serious pollution projects; establish strict energy saving assessment review, project examination and approval accountability system to carry out the high pollution limit energy intensive products export policy; implement the difference electrovalence, clamp down on illegal waste of resources, environmental pollution, small oil refinery, chemical and other similar projects.

The all-round construction energy saving. Strictly enforce energy saving design standard, all the newly built schools, hospitals, hotels and residential conform to the new standards of heating, heat preservation, saving material and energy saving building. Use new wall materials, promote the use of natural gas, solar and other clean energy. Actively promote energy saving renovation of existing buildings, strengthen the supervision and management of the new building energy saving standards, promote new energy saving wall roofing insulation, energy-saving heating system, energy-saving doors and windows, air conditioning refrigeration, green lighting and renewable energy utilization of building energy- saving technologies and products, actively and steadily promote the reform of heating management, gradually implementing metering system for household heating.

Accelerate the transportation energy conservation. Implement bus priority strategy, and gradually establish a urban public transport system composed mainly by bus, taxi and other transportation as addition. Actively develop "Energy saving bus", vigorously promote new energy vehicles and speed up the development of gas transportation vehicles, speed up the scrappage and update of old cars, build perfect public transport energy saving system.

Use natural resources efficiently. Promote water- saving irrigation and dry land farming, encourage water reuse and wastewater recycling. Limit the production, sales and use of water-wasting appliances, encourage public use of water-saving appliances. Conserve and intensively utilize cultivated land, improve land productivity, speed up the utilization and reclamation of intertidal wasteland. Strengthen chemical industry, building materials, mechanical and electronic, paper and other raw material consumption management; promote alternative conservation and comprehensive utilization of lumber, study and formulate measures to limit the excessive packaging products and to promote bulk cement use. Improve the efficiency of mineral resource recovery, rationally exploit energy and mineral resources such as petroleum, gas, geothermal, bittern, research and development deep processing technology to improve product added value. 


\section{Drive Ecological Construction of Oilfield and} Coordinated Recycling Economy Development of Oilfield and Local

Strengthen the cleaner production in Shengli oilfield. Gradually reduce the pollution to the environment of oil exploration and exploitation process by adoption of cleaner production technologies. In the development of sea oil, protect the original environment around the outer edge of the Yellow River delta. In nature reserve, improve the technologies of petroleum production, limit the well number of petroleum production, narrow the cover area of the wells as far as possible, and reduce the negative effect on the environment to the least.

Make more efforts for cooperation of Shengli oilfield and local economy. Develop all kinds of petrochemical products with the strengths of abundance with resources of petroleum and gas in the Yellow River delta and the characteristics of petrochemical industry chain being long, promote the petroleum and gas exploitation forward, and backward drive the producing of synthetic fiber, plastic, rubber and the chemical productions of them. Vigorously develop petroleum chemical and salt chemical industry group, utilizing comprehensively and complemently oil and gas resources and bittern resources, and each other.

\section{Develop the Marine Circular Economy}

Taking Shandong peninsula blue economic zone construction as an opportunity, insist on the marine resources development and marine, coastal environment protection and vigorously promote the comprehensive utilization of seawater and extend sea salt producing and processing, sea salt chemical industry, aquaculture and other marine economic cycle chain, salt chemical industry base as well as the standard seawater aquaculture base. Speed up the development of strategic emerging marine industries, cultivating equipment of oil production in offshore oil drilling equipment manufacturing, marine biological medicine, marine biological molecular materials, marine functional foods, marine oil and gas resources development, petrochemical industry, fine chemical industry, and promote formation of low emissions, recyclable, large-scale ocean circular economy.

\section{E. Construct Ecological City and Create a Circular} Society

Strictly control discharge of pollutants. Strengthen the management of the emission of industrial wasted and polluted water. Strictly monitor and totally control of printing and dyeing, paper making, chemical and thermal pollutants in key industries and key enterprises, such as putting an end to illegal dredge activities, minimizing industrial wasted and polluted water emissions. Strengthen agricultural pollution management; strengthen the comprehensive treatment of scale livestock and poultry farms, agricultural non-point source pollution, construct ecological livestock villages according to the total amount control aim. Complete pollution-control facilities on large-scale farms, livestock manure utilization, realize ecological livestock farm wastewater using or standard discharging. Strengthen urban sewage treatment project construction and improve the treatment rate of urban sewage.

Strengthen the recycling and recovery utilization of garbage. Establish reasonable layout of the garbage collection point and life waste transferring station to speed up the construction of villages and towns' garbage transferring station and gradually extends the garbage collection system to the various natural villages and improve the network of garbage collection.

Make comprehensive renovation of urban river. Take comprehensive measures, such as dredging, sorting, greening to reinforce on riverbanks, control sewage discharge into the river and so on to increase the flood discharge in river drainage capability, improve river water quality, restore and strengthen channel function and strengthen the ecological landscape function of rivers, promote resource development and utilization of rivers in urban areas.

Create a conservation-minded government. Establish government managing system, standard system and organization and coordination mechanism, create a batch of pilot demonstration units, resource conservation official vehicles equipped with standard and perfect management system, encourage purchasing low-emission, low fuel consumption and low emission vehicles. Implement green purchasing and green consumption, and gradually improve the government procurement items, renewable products and recycled products in the proportion of energy saving, water saving, pollution-free green product. Well manage the energy saving of air conditioning, lighting and other office equipment; promote the use of water-saving water valve and the paperless office.

\section{REFERENCES}

[1] X. X. Li, "Circulation economy, the inevitable path of agriculture modernization of China," Ecological Economy, vol. 5, pp. 110-111, 116, 2006 (in Chinese).

[2] Z. J. Feng, "Normative study on circular economy," China Soft Science, vol. 8, pp. 9-21, 2006 (in Chinese).

[3] X. J. Niu and C. H. Li, "Evolution research on strategic coordination between circular economy and new energy strategy," China Soft Science, vol. 12, pp. 146-151, 2012 (in Chinese).

[4] J. Z. Zuo, "Development countermeasures of agricultural circular economy in Anhui province, China," Northern Economy, vol. 17, pp. 70-72, 2012 (in Chinese).

[5] Z. J. Feng and N. L. Yan, "Putting a circular economy into practice in China," Sustainability Science, vol. 2, pp. 95-101, 2007, DOI 10.1007/s11625-006-0018-1.

[6] J. H. Li and K. L. Yu, "A study on legislative and policy tools for promoting the circular economic model for waste management in China," Journal of Material Cycles and Waste Management, vol. 13, pp. 103-112, 2011, DOI 10.1007/s10163-011-0010-4.

[7] M. S. Anderson, "An introductory note on the environmental economics of the circular economy," Sustainability Science, vol. 2, pp. 133-140, 2007, DOI 10.1007/s11625-006-0013-6.

[8] Q. W. Meng and C. S. Ren, "Research on scientific exploitation of marine resources in the constructing process of Shandong Peninsula blue economic zone," Ocean Development and Management, vol. 1, pp. 58-62, 2011 (in Chinese).

[9] Y. F. Li, "The development of the abandoned Yellow River delta, Geographical Research, vol. 10, no. 4, pp. 29-39, 1991 (in Chinese).

[10] (February 2012). Dongying city bureau of statistics. Dongying city national economic and social development statistical bulletin in 2011[EB/OL]. [Online]. Available: http://www.dytjj.com/dytj/news/ 20123216174411 53 411534. shtml. (in Chinese).

[11] J. H. Yin and Z. H. Wang, "Eco-industrial park - the strategic choice of circular economy development of China on industrial level," Industrial Technology \& Economy, vol. 25, no. 1, pp. 9-11, 2006 (in Chinese). 
[12] X. B. Xu, "Research on relations of circular economy mode and sustainable agriculture development," Agriculture Economy, vol. 11, pp. 12-14, 2012 (in Chinese).

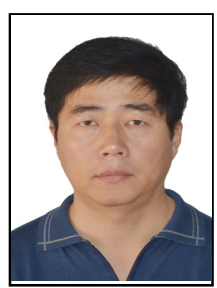

Zhang Xu-Liang was born on May 28, 1971 in Huimin County, Shandong Province, China. He graduated from Ocean University of China in June, 2006 with a doctor's degree of marine geology. His researches mainly focus on geography and wetland ecology.

A previous lecturer during July, 1998 to December, 2000, he has now been working as an associate professor in Geography Department, Normal College, Qingdao University, Shandong Province, China since January, 2001. He is also a postgraduate tutor of environment science in Qingdao University since 2011. He has published a book and more than 40 papers. The book elaborates on restoration and rehabilitation of degraded coastal wetlands in the southern Laizhou Bay, Bohai Sea, China.

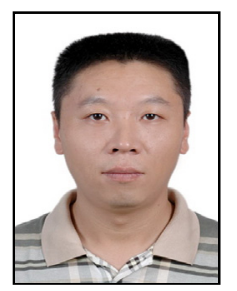

Zhang Zhao-Hui was born in 1971, in Liaoning Province, China, graduated from Ocean University of China and received doctor degree of marine ecology in June, 2003, now researched mainly on marine ecosystem management. Now work as an associate research fellow in the First Institute of Oceanography, State Oceanic Administration, China.

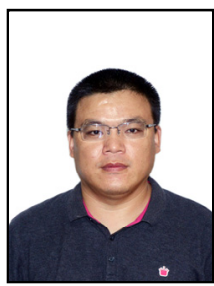

Xu Zong-Jun was born in 1975, in Shandong Province, China, graduated from Ocean University of China and received doctor's degree of marine ecology in June, 2007. His research is now mainly on marine ecology. $\mathrm{He}$ is now working as an associate research fellow in the First Institute of Oceanography, State Oceanic Administration, China.

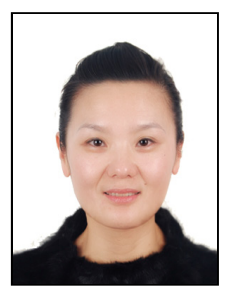

Yao Hai-Yan was born in March, 1974, in Shandong Province, China. She graduated from Shandong Normal University of China and received Master's degree of material science in July, 1998. She now is working on marine information and mangaement. She has worked as a senior engineer since October, 2012 and meanwhile as an engineer in North China Sea Data \& Information Service of SOA since 2001.

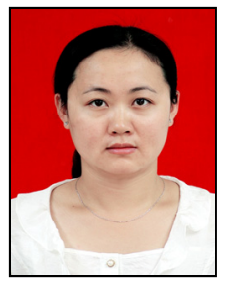

Zheng Ke-Fang was born on February 14, 1980, in Daqing, Heilongjiang Province, China. She graduated from Shandong University of China and received Master's degree of material science in June, 2006. She is now working on marine information and mangaement. She had worked as an assistant engineer from October, 2006 to October, 2009 and has been as an engineer in North China Sea Data \& Information Service of SOA since 2012. 